\title{
An 8-Week Stress Management Program for Older Women: A Pilot Randomized Controlled Trial
}

\author{
Foteini Papageorgiou1, Liza Varvogli' ${ }^{1}$, Theodora Oikonomidi1 ${ }^{1}$ George P. Chrousos ${ }^{1,2 *}$, \\ Christina Darviri ${ }^{*} \#$ \\ ${ }^{1}$ Postgraduate Course Stress Management and Health Promotion, School of Medicine, University of Athens, \\ Athens, Greece \\ ${ }^{2}$ First Department of Pediatrics, Children's Hospital Aghia Sofia, School of Medicine, University of Athens, \\ Athens, Greece \\ Email: f.papageorgiou@yahoo.gr, varvogli@otenet.gr, chrousge@med.uoa.gr, "cdarviri@yahoo.com
}

Received 21 April 2016; accepted 13 June 2016; published 16 June 2016

Copyright (C) 2016 by authors and Scientific Research Publishing Inc.

This work is licensed under the Creative Commons Attribution International License (CC BY).

http://creativecommons.org/licenses/by/4.0/

(c) (i) Open Access

\begin{abstract}
Stress can significantly impair the health of older people, who often face a combination of stressors unique to this age group. This study is a stress management and lifestyle change intervention for women 60 years and older. The participants were randomly assigned to either the intervention group or the control group. The 8-week intervention plan included training in progressive muscle relaxation and guided imagery, abdominal breathing training using biofeedback, physical activity and nutrition counseling, and cognitive restructuring training. Self-report validated measures were used to evaluate perceived stress, depression, health locus of control, and well-being. The intervention group experienced significantly greater reduction in perceived stress $(p<0.001$, $r=0.8)$ and physical and psychological stress symptoms $(p<0.001, r=0.7)$ compared to the control group. The intervention also significantly reduced depressive symptoms and improved quality of life $(p<0.001, r=0.7$ for both variables). The findings of this study confirm the positive effects of multimodal stress management interventions on the mental and physical health of older women. Wellbeing interventions for the elderly should include stress management modules.
\end{abstract}

\section{Keywords}

Depression, Older Women, Relaxation, Stress, Aging

\footnotetext{
${ }^{*}$ These authors contributed equally and share last authorship.

"Corresponding author.
} 


\section{Introduction}

Research interest in mental health and aging is on the rise due to the continuous increase in the proportion of the elderly worldwide (Baltes \& Smith, 2003; Berg, Hassing, McClearn, \& Johansson, 2006). Life expectancy in Greece has reached 78.5 years for men and 83.5 years for women (ELSTAT, 2015). Third age is characterized by a significant number of health problems, including psychological and psychosomatic problems. This gives impetus to research that aims to assist the elderly in spending this life stage with fewer difficulties, greater productivity, and better life quality (Gayle, Iwamasa, \& Hilliard, 1999).

One important factor that impairs the health of older people is stress. Stress occurs when homeostasis is threatened or perceived to be so. Stressful stimuli act on the central nervous system causing stimulation of the hypothalamic-pituitary-adrenal (HPA axis) and the sympathetic nervous system (SNS). Malfunction of these systems leads to increased production of adrenaline, noradrenaline, CRF (corticotropin releasing factor), ACTH (adrenocorticotropic hormone), and cortisol. The stimulation of the HPA axis results in increased levels of cortisol, epinephrine and catecholamine (Chrousos, 2009).

Important stressors for the elderly include caring for a sick spouse, loss of spouse, loss of other relatives and friends, reduction of physical strength, financial problems, social isolation, lack of sense of purpose and productivity, dependence, and difficulties in memory and other cognitive functions (Sharpe, Williams, Granner, \& Hussey, 2007). As long-term stress can increase one’s risk for many health issues, including heart disease, high blood pressure, stroke, gastrointestinal disorders and sleep disorders, keeping stress levels low would be beneficial for the elderly (Holt-Hill, 2009). Studies have shown positive effects of physical exercise (Krause, Goldenhar, Lianc, Jay, \& Daisaku, 1993), abdominal breathing (Yu \& Kim, 2003), massage therapy (Sharpe et al., 2007), progressive muscle relaxation (De Berry, 1981; Yu, Lee, \& Woo, 2007), music therapy (Hansen \& Thomson, 1994), and cognitive behavioral therapy (Ayers, Sorrell, Thorp, \& Wetherell, 2007) as stress management practices for the elderly.

This study tests the effect of a non-pharmaceutical intervention including stress management and lifestyle changes in women aged over 60. The primary aim is to reduce stress levels. We also aim to decrease depressive symptoms, as well as physical and psychological stress symptoms.

\section{Methods}

\subsection{Study Design}

This is a randomized controlled trial on the effects of an 8-week stress management and health promotion intervention for the elderly in a community setting. The study was carried out between December 2013 and February 2014 at a community centre (C.O.P.E.) in Athens, Greece. The inclusion criteria were being female, aged 60 years old or older, and having a membership at C.O.P.E. centre in the Zografou region of Athens, Greece. The exclusion criteria were current practice of other relaxation techniques, use of psychotropic drugs, recent hospitalization, dementia diagnosis, and/or motor disability. The recruited women were randomly assigned to the intervention group or the control group (1:1 allocation ratio) using an online random number generator (random.org). All participants signed an informed consent form. The study received ethical approval and was locally registered by the University of Athens.

\subsection{Intervention}

The multifaceted 8-week intervention included training in progressive muscle relaxation (PMR), guided imagery (GI) and abdominal breathing (AB) (with the use of biofeedback equipment), physical exercise and nutrition counseling, and cognitive restructuring training (CR). During the 8 week study, the participants in the intervention group attended weekly meetings with the researcher. Information was given on exercise, nutrition and cognitive restructuring. Participants in the intervention group practiced PMR, RB and GI initially under the supervision of the researcher, so that detailed instructions could be given. The relaxation exercises were then repeated independently by each participant at home with the use of recorded instructions in the form of a CD. The intervention tools included a CD with 21 minute long audio instructions for AB and PMR, a CD with 20 minute long audio instructions for GI, brochures with information for the benefits of physical activity and healthy dietary habits, a pedometer for self-monitoring of physical activity, and a relaxation diary with which participants could keep track of their at-home relaxation practice. The participants were instructed to practice relaxation techniques 
twice daily using the CDs. The control group attended one educational session on healthy lifestyle habits and stress reduction. This complex intervention comprises of stress management techniques that have been shown to be beneficial for diverse populations, and this intervention has proven to be beneficial for a population of healthy adults in a previous study (Alexopoulos, Zisi, Manola, \& Darviri, 2014).

\subsection{Measures and Statistical Analysis}

The following questionnaires were completed by all participants twice, at the first and last meeting ( ${ }^{\text {th }}$ week):

A self-report questionnaire was used to collect information on socio-demographic variables (such as age, sex, smoking status, educational level, family status, type of employment, Body Mass Index) and stress symptoms. Specifically, a list of 36 physical and psychological symptoms commonly associated with stress in the literature was created. The frequency with which participants experienced each symptom could be rated on a five point Likert-type scale. Lastly the questionnaire collected information on health-related lifestyle habits (such as exercise, diet, and daily routine).

Stress was measured using the Perceived stress scale (PSS-14), measure of the degree to which situations in one's life are appraised as stressful. Each item is rated on a five point Likert-type scale ranging from $0=$ never to 4 = very often (Cohen, Kamarck, \& Mermelstein, 1983). The scale has been validated in the Greek population (Andreou et al., 2011).

The Health locus of control scale (HLC) was used to assess participants' beliefs regarding having control over their health. The 18-item scale has three subscales, namely "internal HLC", "external HLC", and "chance" (HLC-1, HLC2, and HLC-3 respectively). Internal HLC measures the degree in which the individual believes that they are responsible for their health status, while external HLC and chance represent the extent to which others or chance, respectively, are perceived to be the main health determinants. Higher scores indicate higher strength of each type of health belief (Wallston, Wallston, \& DeVellis, 1978).

The Geriatric Depression Scale (GDS) was used to measure depression levels. The scale includes 15 yes or no questions, yielding a total score between zero and 15 . The score can be interpreted as follows: 0 - $4=$ no depression, 5 - 10 = suggestive of a mild depression, and $11-15$ = suggestive of severe depression. The scale has been validated in Greek (Fountoulakis et al., 1999; Yesavage, et al., 1983). Lastly, the WHO-5 Well-being Index was used to measure participants' sense of wellbeing. This short questionnaire consists of five statements that are answered on a five point Likert-type scale, yielding a score between zero and 25, with higher scores indicating a higher level of wellbeing (Heun, Bonsignore, Barkow, \& Jessen, 2001). We needed a sample size of 52 participants for alpha $=0.05,80 \%$ power (beta $=0.20$ ) and 0.8 standard deviations. As we expected some dropouts due to the intervention requirements we aimed to recruit a total of 62 patients. Baseline group characteristics are presented as means and standard deviations, or as absolute and proportion values depending on variable type. For between-group comparisons, the Mann-Whitney U-test was used and the effect size was calculated for each variable. Statistical analyses were performed using the SPSS 20 software for Windows.

\section{Results}

The participant flow chart is shown in Figure 1. Seventy-one women were invited to take part in the study and were informed about its purpose. Sixty-seven of them accepted the invitation. Five participants were excluded due to current medication use. The remaining sample of sixty two participants that met the criteria was randomized into the two groups (intervention group $\mathrm{N}=31$, control group $\mathrm{N}=31$ ). There were no drop outs during the study period.

Table 1 shows the sociodemographic characteristics and baseline measurements of the two groups. The sample consisted of women in their late sixties, the majority of which was married and had attained secondary education. The majority of women were nonsmokers. The between-group comparison reveals that the participants in the two groups did not differ significantly in sociodemographic characteristics and baseline measurements $(p>$ 0.05 for all comparisons), apart from the chance health locus of control (HLC-3) which was significantly higher in the intervention group $(p<0.05)$.

Table 2 shows the between-group comparisons of change in mean values for all outcome measures (final measurement minus baseline measurement for each outcome). The women in the intervention group experienced statistically significant greater reduction in stress levels (PSS-14, $p<0.001, r=0.8$ ). The intervention group also showed significant improvement in depressive symptoms (GDS, $p<0.001, r=0.7$ ), wellbeing (WHO-5, 


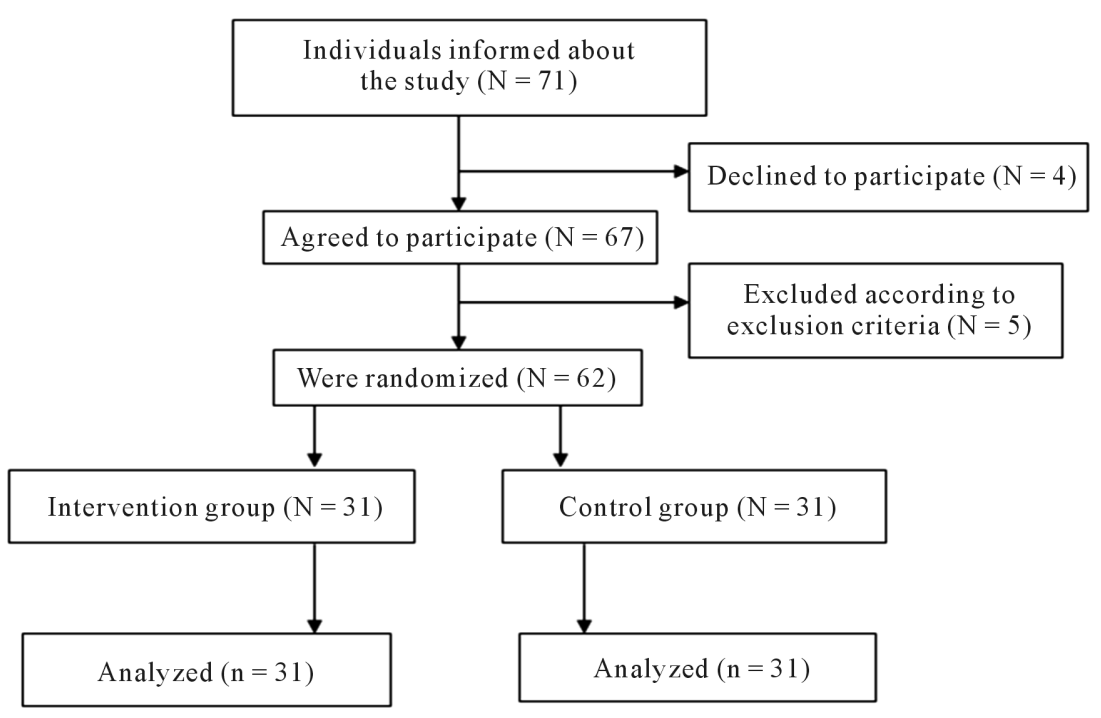

Figure 1. Flowchart of study participants.

Table 1. Demographic characteristics of the sample.

\begin{tabular}{cccc}
\hline Demographic variables & $\begin{array}{c}\text { Intervention Group } \\
(\mathrm{N}=31)\end{array}$ & $\begin{array}{c}\text { Control }(\mathrm{N}=31) \\
\text { Group }\end{array}$ & $p$ value \\
\hline Mean age ( \pm SD) & $69.94 \pm 4.62$ & $68.09 \pm 4.04$ & 0.353 \\
Married N (\%) & $18(58.1)$ & $17(54.8)$ & 1.00 \\
Education & & & \\
Primary N (\%) & $6(19.4 \%)$ & $10(32.3 \%)$ & \\
Secondary N (\%) & $22(71.0 \%)$ & $16(52.3 \%)$ & 0.311 \\
Tertiary N (\%) & $3(9.7 \%)$ & $5(16.1 \%)$ & \\
Smoking & & & \\
NoN (\%) & $21(67.7 \%)$ & $23(74.2 \%)$ & \\
Yes N (\%) & $4(12.9 \%)$ & $2(6.5 \%)$ & 0.779 \\
Past N (\%) & $6(19.4 \%)$ & $6(19.4 \%)$ & \\
Measurements (Mean \pm SD) & & & 0.484 \\
PSS & $28.39 \pm 10.02$ & $23.77 \pm 9.81$ & 0.980 \\
BMI & $25.57 \pm 3.49$ & $25.59 \pm 3.81$ & 0.479 \\
Daily habits & $66.00 \pm 7.07$ & $64.13 \pm 11.37$ & 0.440 \\
Physical stress symptoms & $23.77 \pm 11.02$ & $25.93 \pm 12.22$ & 0.467 \\
Psychological stress symptoms & $20.06 \pm 7.25$ & $20.84 \pm 9.10$ & 0.712 \\
HLC-1 & $20.22 \pm 5.26$ & $22.74 \pm 5.59$ & 0.073 \\
HLC-2 & $20.58 \pm 5.01$ & $22.64 \pm 4.82$ & 0.103 \\
HLC-3 & $18.93 \pm 7.62$ & $15.03 \pm 5.50$ & $0.020^{*}$ \\
GDS & $4.13 \pm 3.26$ & $3.04 \pm 2.76$ & 0.242 \\
\hline
\end{tabular}

${ }^{*} p<0.05$; PSS: Perceived Stress Scale, BMI: Body Mass Index, Daily Habits: self-report questionnaire on exercise, daily routine, and dietary habits, HLC: Health Locus of Control scale (HLC-1: internal subscale, HLC-2, external subscale, HLC-3, chance subscale), GDS: Geriatric Depression Scale, WHO-5: WHO-Five Wellbeing Index. 
Table 2. Change in mean average for all outcomes between the study groups.

\begin{tabular}{|c|c|c|c|c|}
\hline Outcomes (Mean \pm SD) & Intervention Group $(\mathrm{N}=31)$ & Control ( $\mathrm{N}=31)$ Group & $p$ value & r effect size \\
\hline PSS & $-4.3 \pm 2.5$ & $0.5 \pm 1.15$ & $<0.001^{*}$ & 0.8 \\
\hline Daily Habits & $10.81 \pm 5.15$ & $0.39 \pm 0.80$ & $<0.001^{*}$ & 0.9 \\
\hline BMI & $-0.31 \pm 0.34$ & $-0.03 \pm 0.23$ & $<0.001^{*}$ & 0.4 \\
\hline Physical Symptoms & $-2.29 \pm 2.35$ & $-0.61 \pm 3.33$ & $<0.001^{*}$ & 0.5 \\
\hline Psychological Symptoms & $-2.58 \pm 1.75$ & $0.68 \pm 2.04$ & $<0.001^{*}$ & 0.8 \\
\hline HLC-1 & $0.22 \pm 1.02$ & $0.22 \pm 0.99$ & 0.982 & 0.003 \\
\hline HLC-2 & $0.29 \pm 1.19$ & $0.06 \pm 0.63$ & 0.632 & 0.06 \\
\hline HLC-3 & $-0.45 \pm 1.59$ & $0.19 \pm 0.79$ & 0.106 & 0.2 \\
\hline GDS & $-0.93 \pm 0.81$ & $0.03 \pm 0.31$ & $<0.001^{*}$ & 0.7 \\
\hline WHO-5 & $5.42 \pm 3.35$ & $-0.13 \pm 2.19$ & $<0.001^{*}$ & 0.7 \\
\hline
\end{tabular}

${ }^{*} p<0.05$; PSS: Perceived Stress Scale, BMI: Body Mass Index, Daily Habits: self-report questionnaire on exercise, daily routine, and dietary habits, HLC: Health Locus of Control scale (HLC-1: internal subscale, HLC-2, external subscale, HLC-3, chance subscale), GDS: Geriatric Depression Scale, WHO-5: WHO-Five Wellbeing Index.

$p<0.001, \mathrm{r}=0.7)$, daily habits score $(p<0.001, \mathrm{r}=0.9)$, physical and psychological stress symptoms score $(p<$ $0.001, \mathrm{r}=0.5$, and $p<0.001, \mathrm{r}=0.8$ ). There was no significant improvement in variables related to the health locus of control (HLC-1, HLC-2, HLC-3).

\section{Discussion}

This randomized controlled study was conducted to assess the effectiveness of an 8-week stress management and health promotion program in older people. It included abdominal breathing (AB), progressive muscle relaxation (PMR), guided imagery (GI), cognitive restructuring (CR), and instructions on healthy eating and exercise habits. The program significantly decreased perceived stress and depression levels, as well as stress-related physical and psychological symptoms and the body mass index. Perceived well-being improved, while there were no significant changes in health locus of control. This was expected, as it may take more than eight weeks to significantly change the health locus of control. These techniques were chosen because they are considered easy and simple for people of all ages and they can easily be integrated in the daily life of elderly people as complementary and/or alternative therapies.

Previous studies confirm the existence of high levels of stress and depression in the elderly. It is estimated that about $1 / 3$ of older people who were admitted into hospitals suffered from depression. In addition, the number of elderly people who commit suicide remains high (Roupa et al., 2009). Structural and biochemical changes that progressively take place in the brain as it ages are considered responsible for the high rates of depression in the elderly (Mandal \& Roe, 2008). The number of daily stressors experienced by older people, such as becoming a caretaker for their partner, experiencing physical disease, admittance in nursing homes, and the higher chance of partner loss, contribute to this (Al-Naggar \& Chen, 2011).

The findings of other studies confirm the effectiveness of relaxation techniques and the adoption of healthy habits in stress reduction and well-being promotion. A study examining the effect of PMR in elderly women who had lost their husbands showed that after five months of training, stress, anxiety and stress-related symptoms had decreased significantly (De Berry, 1981). Another study showed a positive effect of PMR in the reduction of stress in elderly Chinese patients with heart failure (Yu, Lee, \& Woo, 2007). The benefits of AB training with the use of biofeedback were confirmed in a study conducted in elderly patients with hypertension, in which there was significant stress reduction and life quality improvement (Yu \& Kim, 2003). GI has also been shown to improve quality of life and health status in older women (Baird \& Sands, 2006). Several studies have shown the positive effects of physical exercise (Atlantis, Chow, Kirby, \& Singh, 2004; Souza Vale et al., 2009; Krause et al., 1993) in stress management and quality of life. Other studies which applied various stress management techniques, such as cognitive restructuring (Granath, Ingvarsson, Thiele, \& Lundberg, 2006), mindfulness (Smith, 2004), and meditation (Lindberg, 2005), found positive effects on the psychological state of the elderly. 
The combination of stress management techniques applied to this intervention has not been previously tested in this population. Moreover, the fact that no participant abandoned the program is encouraging and shows it is a well-tolerated intervention that can be easily incorporated in one's daily routine. Limitations of our research include that the study was not blinded and that it was not possible to confirm the adherence of the participants to the program. Moreover, the sample for this study was exclusively female. There are numerous gender differences in psychobiological aspects of stress, coping methods, and behavioural outcomes of stress in older populations (Kudielka, Buske-Kirschbaum, Hellhammer, \& Kirschbaum, 2004; Sacco, Bucholz, \& Harrington, 2014; Yeh, Huang, Chou, \& Wan, 2009). Significantly more females than males attended the municipal community centre where the sample was recruited. Therefore we chose to recruit females only in order to avoid unequal gender representation in our sample which would make the interpretation of findings difficult and limit generalisability. We encourage the replication of the study on males. Lastly, the intervention was tested against a minimal intervention control group. Therefore the control group attended an educational session, as well as meetings to complete measurements at the beginning and the end of the intervention period, while the intervention group attended eight meetings in total. Meeting with the researcher constitutes a form of socializing, and the difference in frequency could have a more pronounced positive impact on depression scores for the intervention group. It is suggested that further randomized studies with larger sample size be undertaken in order to confirm these findings.

\section{Conclusion}

To summarize, this stress management program can lower stress and depression levels and improve wellbeing. As this intervention does not require special equipment or infrastructure, we believe that it could easily be incorporated in standard community centre or care home activities, thereby making a contribution to the mental and physical health of older women, providing them with useful coping mechanisms.

\section{References}

Alexopoulos, E. C., Zisi, M., Manola, G., \& Darvin, C. (2014). Short-Term Effects of a Randomized Controlled Worksite Relaxation Intervention in Greece. Annals of Agricultural and Environmental Medicine, 21, 382-387. http://dx.doi.org/10.5604/1232-1966.1108609

Al-Naggar, A., \& Chen, R. (2011). Stress and Coping Strategies among Retired People in Malaysia: A Qualitative Study. ASEAN Journal of Psychiatry, 12, 143-147.

Andreou, E., Alexopoulos, E. C., Lionis, C., Varvogli, L., Gnardellis, C., Chrousos, G. P., \& Darviri, C. (2011). Perceived Stress Scale: Reliability and Validity Study in Greece. International Journal of Environmental Research and Public Health, 8, 3287-3298. http://dx.doi.org/10.3390/ijerph8083287

Atlantis, E., Chow, C. M., Kirby, A., \& Singh, M. F. (2004). An Effective Exercise-Based Intervention for Improving Mental Health and Quality of Life Measures: A Randomized Controlled Trial. Preventive Medicine, 39, 424-434. http://dx.doi.org/10.1016/j.ypmed.2004.02.007

Ayers, C. R., Sorrell, J. T., Thorp, S. R., \& Wetherell, J. L. (2007). Evidence-Based Psychological Treatments for Late-Life Anxiety. Psychology and Aging, 22, 8-17. http://dx.doi.org/10.1037/0882-7974.22.1.8

Baird, C. L., \& Sands, L. P. (2006). Effect of Guided Imagery with Relaxation on Health-Related Quality of Life in Older Women with Osteoarthritis. Research in Nursing \& Health, 29, 442-451. http://dx.doi.org/10.1002/nur.20159

Baltes, P. B., \& Smith, J. (2003). New Frontiers in the Future of Aging: From Successful Aging of the Young Old to the Dilemmas of the Fourth Age. Gerontology, 49, 123-135. http://dx.doi.org/10.1159/000067946

Berg, A. I., Hassing, L. B., McClearn, G. E., \& Johansson, B. (2006). What Matters for Life Satisfaction in the Oldest Old? Aging \& Mental Health, 10, 257-264. http://dx.doi.org/10.1080/13607860500409435

Chrousos, G. P. (2009). Stress and Disorders of the Stress System. Nature Reviews Endocrinology, 5, 374-381. http://dx.doi.org/10.1038/nrendo.2009.106

Cohen, S., Kamarck, T., \& Mermelstein, R. (1983). A Global Measure of Perceived Stress. Journal of Health and Social Behavior, 24, 385-396. http://dx.doi.org/10.2307/2136404

De Berry, S. (1981). An Evaluation of Progressive Muscle Relaxation on Stress Related Symptoms in a Geriatric Population. The International Journal of Aging and Human Development, 14, 255-269. http://dx.doi.org/10.2190/5C1R-9D61-YG2N-A7LV 
ELSTAT (2015). Living Conditions in Greece. http://www.statistics.gr/documents/20181/1216578/LivingConditionsInGreece_1215.pdf/5740b055-e8e8-4947-a499-146b $\underline{57 f 2 f 455}$

Fountoulakis, K. N., Tsolaki, M., Iacovides, A., Yesavage, J., O’Hara, R., Kazis, A., \& Ierodiakonou, C. (1999). The Validation of the Short Form of the Geriatric Depression Scale (GDS) in Greece. Aging Clinical and Experimental Research, 11, 367-372. http://dx.doi.org/10.1007/BF03339814

Gayle, Y., Iwamasa, G. Y., \& Hilliard, K. M. (1999). Depression and Anxiety among Asian American Elders: A Review of the Literature. Clinical Psychology Review, 19, 343-357. http://dx.doi.org/10.1016/S0272-7358(98)00043-9

Granath, J., Ingvarsson, S., Thiele, U., \& Lundberg, U. (2006). Stress Management: A Randomized Study of Cognitive Behavioral Therapy and Yoga. Cognitive Behaviour Therapy, 35, 3-10. http://dx.doi.org/10.1080/16506070500401292

Hansen, S. B., \& Thomson, L. W. (1994). Effects of a Music Therapy Strategy on Depressed Older Adults. Journal of Gerontology, 49, 265-269. http://dx.doi.org/10.1093/geronj/49.6.P265

Heun, R., Bonsignore, M., Barkow, K., \& Jessen, F. (2001). Validity of the Five-Item WHO Well-Being Index (WHO-5) in an Elderly Population. European Archives of Psychiatry and Clinical Neuroscience, 251, 27-31. http://dx.doi.org/10.1007/BF03035123

Holt-Hill, S. A. (2009). Stress and Coping among Elderly African-American. Journal of National Black Nurses Association, 20, 1-12.

Krause, N., Goldenhar, L., Lianc, J., Jay, G., \& Daisaku, M. (1993). Stress and Exercise among the Japanese Elderly. Social Science and Medicine, 36, 1429-1441. http://dx.doi.org/10.1016/0277-9536(93)90385-H

Kudielka, B. M., Buske-Kirschbaum, A., Hellhammer, D. H., \& Kirschbaum, C. (2004). HPA Axis Responses to Laboratory Psychosocial Stress in Healthy Elderly Adults, Younger Adults, and Children: Impact of Age and Gender. Psychoneuroendocrinology, 29, 83-98. http://dx.doi.org/10.1016/S0306-4530(02)00146-4

Lindberg, D. A. (2005). Integrative Review of Research Related to Meditation, Spirituality, and the Elderly. Geriatric Nursing, 26, 372-377. http://dx.doi.org/10.1016/j.gerinurse.2005.09.013

Mandal, B., \& Roe, B. (2008). Job Loss, Retirement and the Mental Health of Older Americans. Journal of Mental Health Policy and Economics, 11, 167-176.

Roupa, Z., Tatsiou, I., Tsiklitara, A., Koulouri, A., Nikas, M., Mpiskini, I., \& Sotiropoulou, P. (2009). Anxiety and Depression among Elderly in the Community. Interscientific Health Care, 1, 61-66.

Sacco, P., Bucholz, K. K., \& Harrington, D. (2014). Gender Differences in Stressful Life Events, Social Support, Perceived Stress, and Alcohol Use among Older Adults: Results from a National Survey. Substance Use \& Misuse, 49, 456-465. http://dx.doi.org/10.3109/10826084.2013.846379

Sharpe, P. A., Williams, H. G., Granner, M. L., \& Hussey, J. R. (2007). A Randomized Study of the Effects of Massage Therapy Compared to Guided Relaxation on Well-being and Stress Perception among Older Adults. Complementary Therapies in Medicine, 15, 157-163. http://dx.doi.org/10.1016/j.ctim.2007.01.004

Smith, A. (2004). Clinical Uses of Mindfulness Training for Older People. Behavioural and Cognitive Psychotherapy, 32, 423-430. http://dx.doi.org/10.1017/S1352465804001602

Souza Vale, R. G., Oliveira, R. D., Pernabucco, C., Meneses, Y., Novaes, J., \& Andrade, A. (2009). Effects of Muscle Strength and Aerobic Training on Basal Serum Levels of IGF-1 and Cortisol in Elderly Women. Archives of Gerontology and Geriatrics, 49, 343-347. http://dx.doi.org/10.1016/j.archger.2008.11.011

Wallston, K. A., Wallston, B. S., \& DeVellis, R. (1978). Development of the Multidimensional Health Locus of Control (MHLC) Scales. Health Education \& Behavior, 6, 160-170. http://dx.doi.org/10.1177/109019817800600107

Yeh, S. C. J., Huang, C. H., Chou, H. C., \& Wan, T. T. (2009). Gender Differences in Stress and Coping among Elderly Patients on Hemodialysis. Sex Roles, 60, 44-56. http://dx.doi.org/10.1007/s11199-008-9515-2

Yesavage, J. A., Brink, T. L., Rose, T. L., Lum, O., Huang, V., Adey, M., \& Leirer, V. O. (1983). Development and Validation of a Geriatric Depression Screening Scale: A Preliminary Report. Journal of Psychiatric Research, 17, 37-49.

http://dx.doi.org/10.1016/0022-3956(82)90033-4

Yu, D. S., Lee, D. T., \& Woo, J. (2007). Effects of Relaxation Therapy on Psychologic Distress and Symptom Status in Older Chinese Patients with Heart Failure. Journal of Psychosomatic Research, 62, 427-437.

http://dx.doi.org/10.1016/j.jpsychores.2006.10.012

Yu, S. J., \& Kim, K. S. (2003). The Effects of Abdominal Relaxed Breathing Exercises Using Biofeedback on Stress Response and Blood Pressure in Elderly People with Hypertension. Journal of Korean Academy of Fundamentals of Nursing, $10,14-22$. 


\section{Submit or recommend next manuscript to SCIRP and we will provide best service for you:}

Accepting pre-submission inquiries through Email, Facebook, Linkedin, Twitter, etc A wide selection of journals (inclusive of 9 subjects, more than 200 journals)

Providing a 24-hour high-quality service

User-friendly online submission system

Fair and swift peer-review system

Efficient typesetting and proofreading procedure

Display of the result of downloads and visits, as well as the number of cited articles

Maximum dissemination of your research work

Submit your manuscript at: http://papersubmission.scirp.org/ 